\title{
Evaluation of the usefulness of maternal mortality ratio for monitoring long-term effects of a disaster: case study on the Bam earthquake
}

F. Zolala

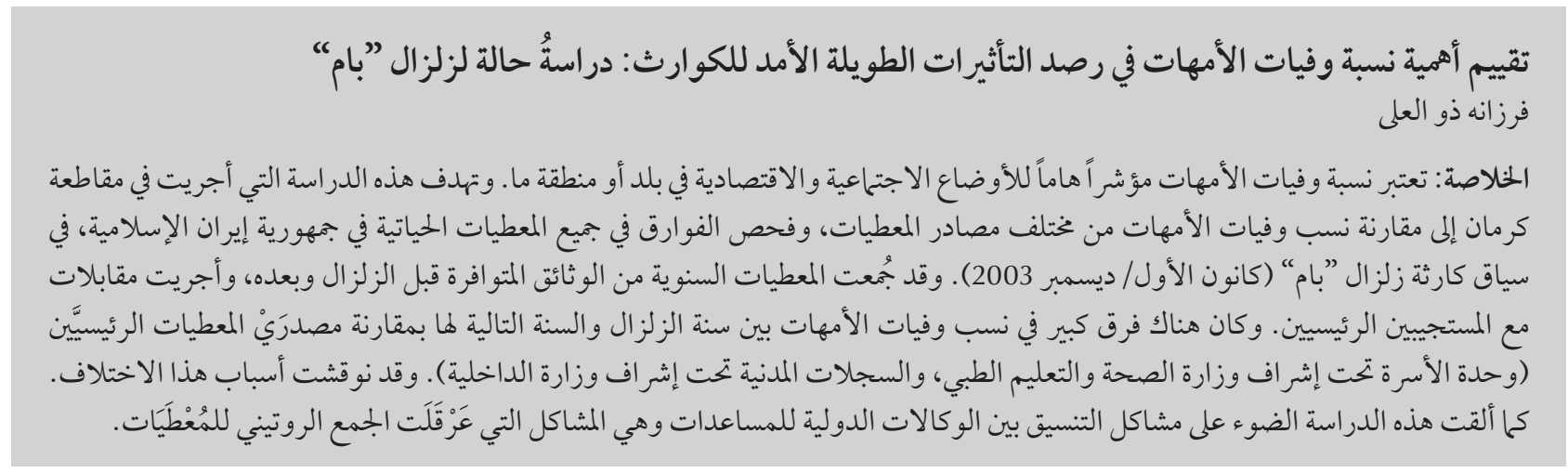

ABSTRACT The maternal mortality ratio is an important indicator of socioeconomic conditions in a country or area. This study in Kerman province aimed to compare maternal mortality ratios from different data sources and examine deficiencies in vital data collection in the Islamic Republic of Iran in the context of the Bam earthquake disaster (December 2003). Annual data were collected from documents before and after the earthquake and interviews were conducted with key informants. There was a large difference in maternal mortality ratios in the year of the earthquake and the year after the earthquake comparing the 2 main data sources (the family unit under the supervision of the Ministry of Health and Medical Education and the civil registry under the supervision of the Ministry of Interior). The reasons for this are discussed. This study also highlighted problems in collaboration between international aid agencies that hindered routine data collection.

Évaluation de l'utilité du taux de mortalité maternelle pour le suivi des effets à long terme d'une catastrophe naturelle : étude de cas du tremblement de terre de Bam

RÉSUMÉ Le taux de mortalité maternelle est un indicateur important de la situation socioéconomique d'un pays ou d'une zone géographique. Cette étude, effectuée dans la province de Kerman (République islamique d'Iran), visait à comparer les taux de mortalité maternelle de différentes sources et à examiner les faiblesses du recueil des données vitales iraniennes, dans le contexte de la catastrophe du tremblement de terre de Bam en décembre 2003. Les données annuelles ont été collectées à partir de documents antérieurs et postérieurs au tremblement de terre et des entretiens ont été réalisés avec d'importants fournisseurs d'information. Des différences significatives ont été observées dans le taux de mortalité maternelle de l'année du tremblement de terre et celui de l'année suivante, si l'on compare les deux principales sources de données : le Centre familial, supervisé par le ministère de la Santé et de l'Enseignement médical, et les registres d'état civil, placés sous la tutelle du ministère de l'Intérieur. Les raisons expliquant ces différences sont présentées dans l'article. La présente étude a également souligné les problèmes de collaboration entre les organismes d'aide internationaux qui entravent le recueil des données de routine. 


\section{Introduction}

According to the World Health Organization (WHO) about 2 billion people were affected by disasters and 600000 lost their lives in the 1990s alone [1]. On average 60000 people die and 250000000 are affected by disasters annually $[2,3]$. Disasters are not only a challenge to society in the immediate aftermath [4] they also have many long-term adverse effects. However, with the exception of mental health, the long-term effects of disasters on health have not received sufficient attention [5]. It has been argued that the health effects of a disaster are more severe for women than for men, as many of the disadvantages that women face in non-disaster conditions [6] are exacerbated in disaster situations, due to many women's lack of access to resources and control over decision-making [7]. Apart from the short-term effect of a disaster on safe motherhood-for example, the rate of preterm delivery has been shown to increase in the 48 hours after an earthquake [8] — there are concerns about the quantity and quality of reproductive health facilities and staff for women living in rescue camps $[9,10]$.

Health indicators are a useful tool to inform policy-making [11]. The maternal mortality ratio (MMR) is an important indicator of socioeconomic conditions in a country or area and could be useful for monitoring the longterm effects of a disaster on the health system and society. This is because maternal mortality is likely to be affected by changes in women's living conditions and access to health facilities after a disaster. In addition, it reflects socioeconomic factors that could be affected by a disaster and need considerable time to rehabilitate $[12,13]$.

The Islamic Republic of Iran is one of the most disaster-prone countries in the world. In December 2003, a very severe earthquake destroyed Bam, an ancient city on an old trade route. The earthquake itself left huge numbers of people dead or injured, and the collapse of the physical and economic infrastructure disrupted the health care system and left many people living in temporary accommodation for extended periods of time after the quake $[14,15]$. This study aimed to compare MMRs from different data sources from before and after the Bam earthquake and to examine deficiencies in vital data collection in the Islamic Republic of Iran both routinely and in disaster situations.

\section{Methods}

This study was a part of a larger study carried out in Bam, a town located in Kerman province, and in Kerman city, the centre of Kerman province. The original study was a mix of qualitative and quantitative methods, with data collected from documents and via interviews with key informants. Permission to conduct the study was obtained from the deputy for health and the civil registry.

\section{Data collection}

This paper reports data on annual maternal mortality collected from 2 years prior to the Bam earthquake (March 2001 to March 2003), the year of the earthquake (March 2003 to March 2004) and the following 3 years (March 2004 to March 2007).

\section{Data sources}

The registration of vital data in the Islamic Republic of Iran has been discussed in more details in an earlier paper by the same author [16].

There are 2 official sources of mortality data, including maternal deaths, in the Islamic Republic of Iran: the provincial statistics unit under the supervision of the Ministry of Health and Medical Education (MOHE) (established at the medical science university in each province) and the civil registry under the supervision of the Ministry of Interior. In addition, maternal deaths are collected through the family unit of the MOHE (also established at the medical science university in each province).

The only official source for live births in the Islamic Republic of Iran is the civil registry. However, due to the low accuracy of data at the civil registry [16] and the almost nationwide coverage of vaccination, health staff in the Islamic Republic of Iran prefer to use the number of children who received the first dose of polio vaccine as the surrogate for the number of live births [17].

\section{Maternal mortality ratios}

In the present study maternal mortality data from these 3 different sources (the family unit at Kerman Medical University, the statistics unit at Kerman Medical University and the civil registry) were extracted. The civil registry and the family unit held the data for the whole period of the study (2001-07), while at the statistics unit data were available only for a 3-year period (2004-07). The statistics unit data therefore could not be used to study maternal mortality before and after the earthquake but because more detailed data was recorded there it provided an opportunity to carry out case-matching with the family unit data.

The MMR is expressed as the number of maternal deaths per 100000 live births. MMRs based on data from the family unit were calculated using the maternal deaths records for Bam as the nominator and the number of children who received the first polio vaccination in Bam as the denominator. MMRs for the civil registration were estimated by the number of maternal deaths and live births recorded at the civil registry.

The data obtained from different sources were not in the same format. The data from the family unit were extracted from the maternal death files. The files provided a variety of data including medical history and demographic and personal information. The author extracted only the personal and demographic characteristics of cases. 


\section{Case comparisons}

It was interesting to know if the data recorded varied across different organizations. Because the data at the civil registry are not recorded for individuals, a crossmatch comparison to check if these 2 organizations had captured the same deaths was not possible. However, the data from the family unit and the statistics unit, which are both under the same organization (the MOHE) were matched. Data at the statistics unit were available for only 3 years and so the data from the family unit and the statistics unit from 2004-07 were matched caseby-case based on the common items recorded.

\section{Organizational strategies}

The strategy of each organization after the earthquake for data collection was examined through interviews with key informants who were involved in data collection and processing, both directly as data collectors and data processors and indirectly as policy-makers.

\section{Data analysis}

The data from the civil registry and the family unit were entered into a Microsoft Excel database in a format similar to that of the civil registry. The data from the statistics unit, which were originally input into Microsoft Access, were exported into Microsoft Excel. Then the data in Farsi were coded into English. Afterwards they were exported into SPSS, version 13 before recoding. The final data were grouped similarly to the output of the vital registry crosstabulations.

\section{Results}

\section{Maternal mortality ratios}

The estimated MMRs from data recorded at the civil register and the family unit over the study period are presented in Figure 1. There was a remarkable difference between the 2 data sources in MMRs in the year of the earthquake (March 2003-March 2004) and the year after the earthquake (March 2004-March 05). While the civil registry showed the highest MMR in the year of the earthquake, the family unit showed the second lowest MMR that year. However, the MMR rose at the family unit the year after the earthquake. Surprisingly, the civil registry presented one of the lowest MMRs in the year after the earthquake.

These contradictions can be attributed to inconsistencies in the denominators or the nominators or both. Therefore the data used for calculation of MMRs were explored and compared in Table 1. The data indicate that the number of live births recorded at the family unit (ranging from 3258 to 5537) were considerably higher than those for the vital registry over the same period (ranging from 2479 to 3948). The number of maternal deaths recorded was also higher in the family unit in comparison with the vital registry, for every year except the year of the earthquake (2003-04), which was 2 for the former and 10 for the latter.

\section{Case matching}

The maternal deaths were matched case-by-case at the family unit and the statistics unit for the years when data were available at both sources (2004-07). The total number of deaths recorded in the family unit was 11 while in the statistics unit it was 8. Data on age, place of residence and date of death were compared for the 8 deaths reported by both sources. In 3 cases the mother's age did not match, in 4 cases the date of death was not consistent and in 2 cases the mother's place of residence was different.

\section{Organizational strategies}

Following the Bam earthquake, the civil registry reacted quickly to register the deaths by establishing temporary branches of the civil registry in different areas of Bam. The government encouraged registration by offering a remuneration. However, the interviews with key informants revealed that if all family members had died, any relatives or neighbours could report the deaths.

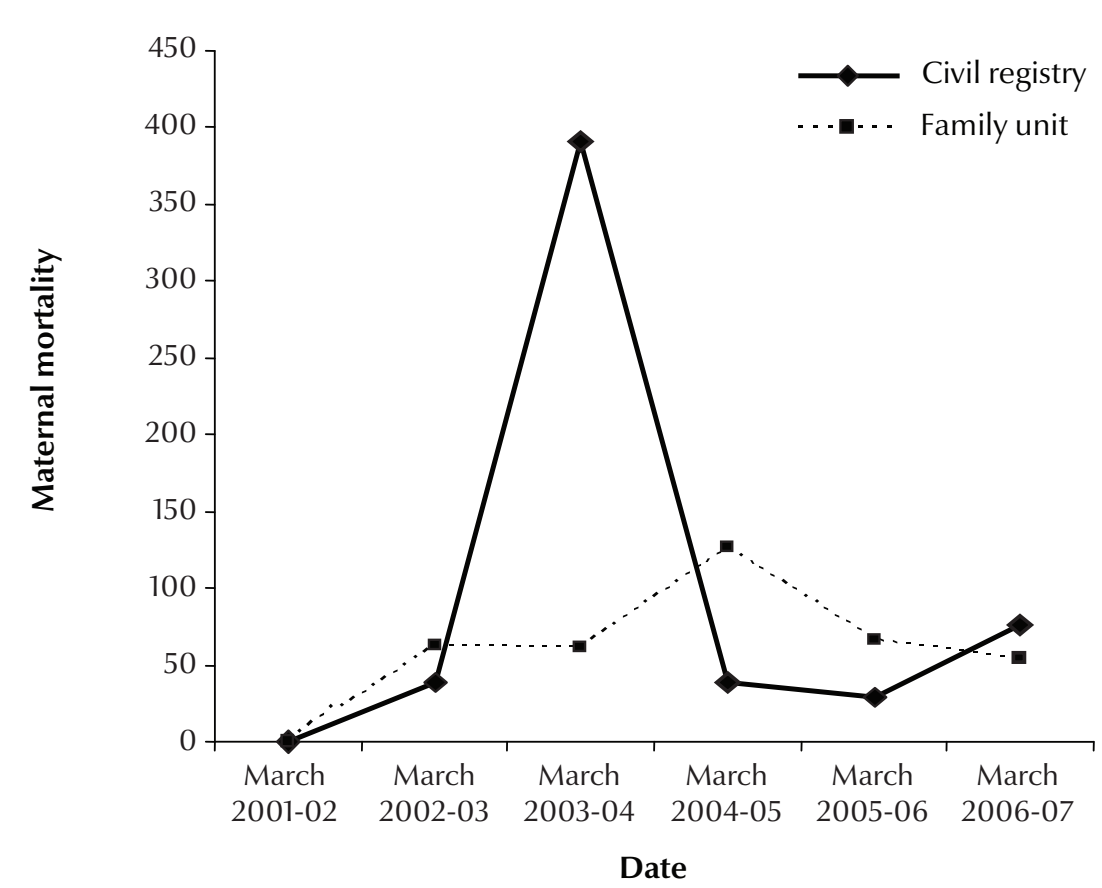

Figure 1 Pattern of maternal mortality ratios (per 100000 deaths) in Bam according to different data sources (the civil registry and the family unit) from March 2001 to 2007 


\begin{tabular}{|c|c|c|c|c|c|c|}
\hline \multirow[t]{3}{*}{ Year } & \multicolumn{3}{|c|}{ Civil registry } & \multicolumn{3}{|c|}{ Family unit } \\
\hline & $\begin{array}{l}\text { Maternal } \\
\text { deaths }\end{array}$ & Live births & MMR & $\begin{array}{l}\text { Maternal } \\
\text { deaths }\end{array}$ & Live births & MMR \\
\hline & No. & No. & /100 000 live births & No. & No. & /100 000 live births \\
\hline 2001-02 & 0 & 2479 & 0 & 0 & 5075 & 0 \\
\hline 2002-03 & 1 & 2616 & 38 & 3 & 4771 & 63 \\
\hline 2003-04 & 10 & 2562 & 390 & 2 & 3258 & 61 \\
\hline 2004-05 & 1 & 2575 & 39 & 5 & 3590 & 127 \\
\hline 2005-06 & 1 & 3466 & 29 & 3 & 4543 & 66 \\
\hline 2006-07 & 3 & 3948 & 76 & 3 & 5537 & 54 \\
\hline
\end{tabular}

Therefore double registration and misregistration of living people were mentioned as problems with this system of registration. The problems with death records immediately after the earthquake have been discussed elsewhere [18].

The interviews at the medical sciences university illustrated another facet of the effects of the earthquake on the data collection system. It was reported that the university had not recorded those deaths which happened immediately after the earthquake. This was explained as being due to the devastating effects of the earthquake on the health care system. Entire workplaces and their equipment were destroyed. Respondents stated that there was long time delay before places of work and equipment became re-established.

The interviews at the medical university also found that following the earthquake the local health staff worked with the International Red Cross/Red Crescent organization for a considerable length of time. During this period they did not send data on births and deaths to Kerman Medical Sciences University, as the data were collected by the Red Cross/Red Crescent emergency teams. Data were initially recorded in English and later in Farsi, the official language of the Islamic Republic of Iran. Reporting data in a different language than the language of a country may limit the ability of the host country to use the data, due to lack of familiarity of regular staff with English language and the need for translation to make the data understandable. Respondents also pointed out that due to the extraordinary nature of the earthquake, the health system was overstretched trying to deal with contagious diseases. Concerns about contagious diseased diverted resources and attention away from routine data collection towards detecting and reporting of diseases.

Immediately after the Bam earthquake, due to the extraordinary scale of the disaster, Kerman Medical University, which used to have a supervisory role, was unable to continue with this role. It therefore provided different support for wide range of aid groups, national and international, and the situation was managed directly at the national level. Changing the role of the medical sciences university from a supervisory to a supportive role was perceived by one respondent as another obstacle to accurate recording of data.

\section{Discussion}

In the Islamic Republic of Iran the main policy decisions about health are made in the MOHE. Therefore, the ministry is one of the main data users. However, this study flags up some serious problems that could limit the validity of data collected by the MOHE. One problem is that of deficiencies in the routine collection of data and another is when these problems are exacerbated by a disaster. The data collection problems observed routinely in non-disaster situations have been discussed elsewhere [16].

There are a number of long-term effects of a disaster on the routine collection of data. Several factors hindered the resumption of data collection shortly after this earthquake. First, recovering the routine data collection system to its pre-disaster state took a considerable time. This long recovery time could reflect either limitations in the ability to rehabilitate the system to its pre-disaster state or the university's priority-setting after the earthquake. The latter can be illustrated by 2 issues: in the period immediately after a disaster, there is a tendency for policy-makers to solve daily, short-term problems rather than longer-term problems [19]. Furthermore, there may be little enthusiasm to use data when policy-makers lack the skills and knowledge to use the data and this can hinder the usefulness of the data [20].

Secondly, the effect of the earthquake on living conditions diverted the policy-makers' attention from routine activities to emergency and surveillance actions. Although these tasks are very important in the critical period after a disaster, they should not prevent routine tasks from being undertaken, particularly when the collected data are 
used not only to monitor the longerterm effects of a disaster but also to make governments accountable to the people [21].

Finally, another problem after the earthquake was poor coordination between the national and international aid agencies in sending routine data to the province. Although the role of national and international aid agencies is very important in disaster relief, poor coordination and lack of task definition regarding routine data collection resulted in no data being sent for several months after the Bam earthquake. Needless to say, these data have a vital role in highlighting problems that develop after a disaster and that could have a critical effect on the population's future health. Such data can be used as indicators of the need for health care services and ultimately for planning future responses to similar situations in a developing country.

\section{Conclusion}

This study used epidemiological data to flag up problems found in the collection of health data and the necessity of paying attention to data collection after a natural disaster. It is very important to have the collaboration of international organizations to collate data in the host country. Therefore appropriate strategies are needed to increase awareness of this issue at the national and global level. This can be achieved through international organizations such as the
WHO or Red Cross/Red Crescent organizations.

\section{Acknowledgements}

This project was financially supported by Kerman Medical University. The author recognizes the important collaboration of Kerman Medical University and Bam health network by facilitating access for fieldwork. I would like to acknowledge and thank my supervisor Dr John Forbes for his professional guidance and encouragement. I also acknowledge the contribution from Kerman Medical University staff and Bam health network for donating their time to be interviewed.

\section{References}

1. Gender and health in disasters. Geneva, World Health Organization, 2002 [factsheet] (http://www.who.int/gender/other_ health/en/genderdisasters.pdf, accessed 2 October 2011).

2. White $\mathrm{P}$ et al. Disaster risk reduction: a development concern. $A$ scoping study on links between disaster risk reduction, poverty and development. London, Department for International Development, 2005.

3. Guha DS, Hargitt D, Hoyois P. Thirty years of natural disasters 1974-2003: the numbers. Brussels, Centre for Research on the Epidemiology of Disasters, 2004.

4. Charvériat C. Natural disasters in Latin America and the Caribbean: an overview of risk. Washington DC, Inter-American Development Bank, 2007.

5. Searman J. The effects of disaster on health: a summary. Disasters, 1980, 4(1):14-18.

6. Beneria L. Reproduction, production and the sexual division of labour. Cambridge Journal of Economics, 1979, 3:203-225.

7. Gender and natural disasters: why are women more vulnerable? Washington DC, Pan-American Health Organization, 2000 [factsheet] (http://www.paho.org/English/DPM/GPP/GH/ genderdisasters.pdf, accessed 2 October 2011).

8. Weissman A et al. The influence of increased seismic activity on pregnancy outcome. European Journal of Obstetrics, Gynecology, and Reproductive Biology, 1989, 31:233-236.

9. Krause S. Assessment of reproductive health for refugees in Zambia. Zambia, Women's Commission for Refugee Women and Children, 2001.

10. Luka T. Reproductive health services for Somali refugees in eastern Ethiopia. Addis Ababa, United Nations Population Fund, 1999.

11. AbouZahr C, Adjei S, Kanchanachitra C. From data to policy: good practices and cautionary tales. Lancet, 2007, 369:1039-1046.
12. Graham WJ et al. The familial technique for linking maternal death with poverty. Lancet, 2004, 363:23-27.

13. Onwudiegwu $U$. The effect of a depressed economy on the utilisation of maternal health services: the Nigerian experience II. Journal of Obstetrics and Gynaecology, 1997, 17:143-148.

14. Tierney $\mathrm{K}$ et al. Social and public policy issues following the 2003 Bam, Iran earthquake. Earthquake Spectra, 2005, 21:S513-534.

15. Ashtiany MG, Mousavi R. History, geography, and economy of Bam. Earthquake Spectra, 2005, 21:S3-11.

16. Zolala F. Health information systems in the Islamic Republic of Iran: a case study in Kerman province. Eastern Mediterranean Health Journal, 2011, 17(9):679-683.

17. Ghassemi H, Harrison G, Mohammad K. An accelerated nutrition transition in Iran. Public Health Nutrition, 2002, 5(1A):149-155.

18. Zolala F. Data collection after massive natural disasters (focusing on Bam earthquake, Iran). Disaster Prevention and Management, 2010, 19(5):541-547.

19. Sauerborn R. Using information to make decision. In: Lippeveld T, Sauerborn R, Bodart C, eds. Design and implementation of health information systems. Geneva, World Health Organization, 2000.

20. Sæbø J, Titlestad O. Evaluation of a bottom-up action research approach in a centralised setting: HISP in Cuba. In: Proceedings of the 37th Hawaii International Conference on System Sciences, 2004 (http://ieeexplore.ieee.org/ iel5/8934/28293/01265384.pdf?arnumber $=1265384$, accessed 2 October 2011).

21. Cibulskis RE, Hiawalyer G. Information systems for health sector monitoring in Papua New Guinea. Bulletin of the World Health Organization, 2002, 80:752-758. 